\title{
On the future of South African Journal of Industrial Psychology
}

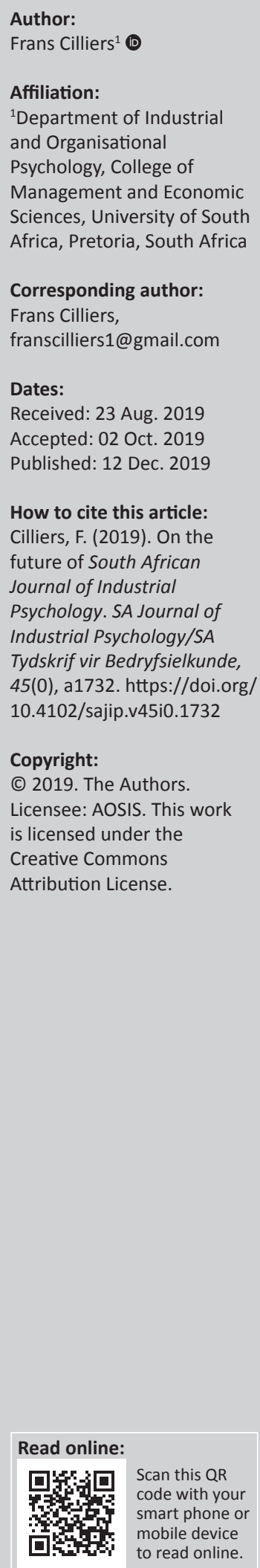

\section{Copyright:}

(C) 2019. The Authors. Licensee: AOSIS. This work is licensed under the Creative Commons Attribution License.

Problemification:Quantitative, qualitative and mixed method research all have a place in industrial and organisational psychology (IOP) research. Sometimes, the impression that is created is that the one is favoured over the other in the manner in which arguments are formulated.

Implications: If an article suggests a strong preference for one specific research method, it creates a split in the sense of what good IOP research represents.

Purpose: The purpose is to create an awareness about how specific research methodologies are positioned in articles as if one is superior to another.

Recommendation: It is recommended that the South African Journal of Industrial Psychology (SAJIP) will remain unbiased towards this situation and maintain the necessary balance.

Keywords: Complex statistical analysis; Quantitative; Qualitative; Competitive dynamic; Inclusion or exclusion dynamic; Complexity of the human psyche.

\section{Introduction}

Quantitative research in industrial and organisational psychology (IOP) has developed impressively over the last few years especially in terms of the application of extremely technical and complex statistical analysis (Efendic \& Van Zyl, 2019). Similarly, interesting developments in qualitative research designs and methodology have come to the fore (Long, 2013, 2016; Thorne, 2016). At the same time, mixed research methods are being increasingly used. The South African Journal of Industrial Psychology (SAJIP) needs to be applauded for publishing excellent research articles employing all of the above research types, methodologies and designs.

I would like to share my opinion on the article by Efendic and Van Zyl (2019) on reproducibility and replicability, as an example of how I see the impact of developments in quantitative research methods in IOP. Upon reading the article, I realised that I do not understand the content of this article on a 'good-enough' level (Cytrynbaum \& Noumair, 2004) to be able to voice an opinion about its merits and contribution to IOP (as I was asked to do by the SAJIP editors). I admit that this statement says more about me than about the article - maybe I should have stayed in closer contact with developments in statistical analysis or have done courses in statistics to enhance my understanding and competence. My point is that while reading the article I missed an opportunity to learn something new about psychology - which is why I read the SAJIP. Maybe there are psychology colleagues in academia and in practice who identify with my position and have similar experiences.

The focus and content of Efendic and Van Zyl's (2019) article provides current concepts amongst the IOP research fraternity at universities. Specifically, the thinking seems to hold that quantitative research and highly sophisticated statistical analysis form a major (and for some the only) part of IOP research. In the conclusion of the article, Efendic and Van Zyl name SAJIP as being at the forefront of both scientific and editorial advancement within Africa, implying quantitative research. I find this admirable and want to congratulate quantitative research colleagues in the South African IOP fraternity by taking up such an informed position (Campbell \& Groenbaek, 2006) within the local and international research space. Being one of the foremost South African academic journals publishing psychological research, I hope that the SAJIP does not support this view to the full extent of its meaning. If so, my concern would be that it would give quantitative research and its highly statistical content an advantage above other designs and methodologies.

Unconsciously (Huffington, Armstrong, Halton, Hoyle, \& Pooley, 2004), the line of thinking can be interpreted as a competitive dynamic with those with an interest in and using other and perhaps 'lesser' research methodologies (e.g., qualitative research). Secondly, it suggests an inclusion or 
exclusion dynamic (Obholzer \& Roberts, 1994) based on the fantasy that research including highly sophisticated quantitative and statistical methods (the numbers) to the exclusion of qualitative or phenomenological methodology (the narratives), represents the real psychological research.

Einstein is known to have said - not everything that counts can be counted, and not everything that can be counted, counts. The purpose of this rebuttal paper is to highlight that IOP researchers and publishers stay cognisant of the complexity of the human psyche, to secure a balance between different research designs and methodologies, and to work in the service of psychology in trying to understand and explain behaviour manifesting in organisations as complex systems.

It is recommended and hoped SAJIP will in future stay focussed on the balance between various research designs and methodologies - as it has become known for. Secondly, a special edition on the development of new methodologies in quantitative, qualitative and mixed methods could be presented to illustrate the SAJIP's unbiased and balanced stance towards various research designs in the publication of IOP research.

\section{Acknowledgements Competing interests}

The author declares that he has no financial or personal relationships which may have inappropriately influenced him in writing this article.

\section{Author's contributions}

F.S. is the sole contributor to this article.

\section{Ethical considerations}

The author confirms that ethical clearance was not needed or required for the study.

\section{Funding information}

This research received no specific grant from any funding agency in the public, commercial or not-for-profit sectors.

\section{Data availability statement}

Data sharing is not applicable to this article as no new data were created or analysed in this study.

\section{Disclaimer}

The views and opinions expressed in this article are those of the author and do not necessarily reflect the official policy or position of any affiliated agency of the author.

\section{References}

Campbell, D., \& Groenbaek, M. (2006). Taking positions in the organisation. London: Karnac.

Cytrynbaum, S., \& Noumair, A. (2004). Group relations reader 3. Jupiter, FL: A.K. Rice Institute.

Efendic, E., \& Van Zyl, L.E. (2019). On reproducibility and replicability: Arguing for open science practice and methodological improvements at the South African Journal of Industrial Psychology. South African Journal of Industrial Psychology, 45(0), a1607. https://doi.org/10.4102/sajip.v45i0.1607

Huffington, C., Armstrong, A., Halton, W., Hoyle, L., \& Pooley, J. (2004). Working below the surface. The emotional life of contemporary organisations. London: Karnac.

Long, S. (2013). Socioanalytic methods. Discovering the hidden in organisations and social systems. London: Karnac.

Long, S. (2016). Transforming experience in organisations: A framework for organisational research and consultancy. London: Karnac.

Obholzer, A., \& Roberts, V.Z. (1994). The unconscious at work. London: Routledge.

Thorne, S. (2016). Interpretive description. Qualitative research for applied practice. New York: Routledge. 